\title{
Incidental Vocabulary Learning through Listening to Teacher Talk
}

Zhouhan Jin, The University of Western Ontario

Supervisor: Webb, Stuart, The University of Western Ontario

A thesis submitted in partial fulfillment of the requirements for the Master of Arts degree in Education

(C) Zhouhan Jin 2018

\section{Recommended Citation}

Jin, Zhouhan, "Incidental Vocabulary Learning through Listening to Teacher Talk" (2018). Electronic Thesis and Dissertation Repository. 5652.

https://ir.lib.uwo.ca/etd/5652

This Dissertation/Thesis is brought to you for free and open access by Scholarship@Western. It has been accepted for inclusion in Electronic Thesis and Dissertation Repository by an authorized administrator of Scholarship@Western. For more information, please contact wlswadmin@uwo.ca. 


\begin{abstract}
Teacher talk plays an important role in the English as a Foreign Language (EFL) classroom because EFL learners have limited access to input and output outside of the classroom (Webb \& Nation, 2017). However, few studies focus on incidental vocabulary acquisition through listening to teacher talk, especially with EFL learners. The present study investigates the effects of teacher talk on incidental vocabulary learning including both single word items and collocations. The relationship between vocabulary learning gains and three factors (frequency of exposure, L1 translation, and note-taking) were also explored. The results indicated that (a) teacher talk contributed to vocabulary learning of both single word items and collocations, (b) using L1 translation to explain target word meanings during teacher talk contributed to larger gains on the immediate posttest, (c) writing target words in notes had a positive effect on learning single words but not collocations, and (d) frequency of occurrence did not affect learning.
\end{abstract}

\title{
Keywords
}

Incidental learning; teacher talk; vocabulary; collocation; frequency of occurrence; L1 translation; note-taking 


\section{Acknowledgements}

I would like to first express my sincere gratitude to my supervisor, Dr. Stuart Webb. Your brilliant guidance and invaluable feedback supported and inspired me throughout my studies. I have learned a lot through your insightful comments, organizing skills, and thoughtful critiques of my work.

I would also like to thank teachers and students in China for helping me collect data. I would never be able to finish this massive work without your help.

The acknowledgments would not be complete without my appreciation to my parents and my boyfriend. When I encountered troubles and felt upset, they were always there, believing in me and supporting me. A big thank goes to my boyfriend, Yifan, who tried his best to help me deal with problems I have encountered during the data analysis stage.

Finally, a special thank goes to Aki, Takumi, Su and every other friend who has enlightened me on my research. You all kept me going and supported me with my thesis. 


\section{Table of Contents}

Abstract

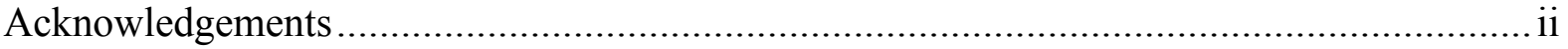

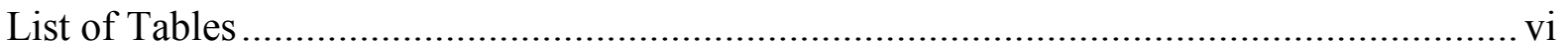

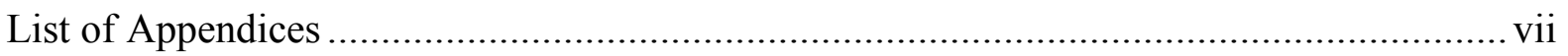

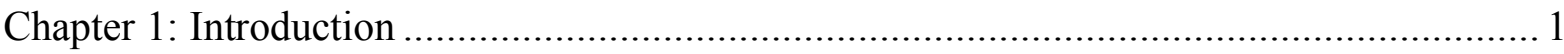

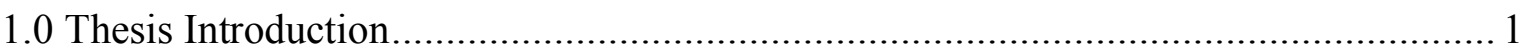

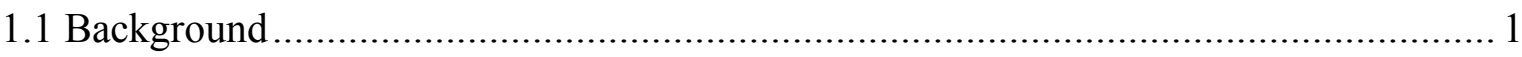

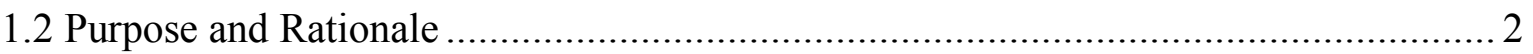

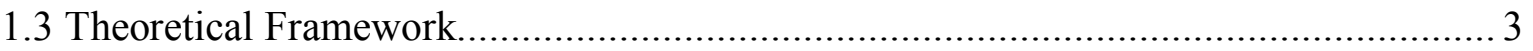

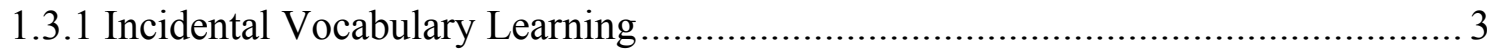

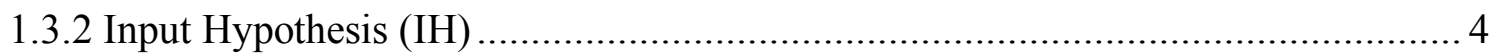

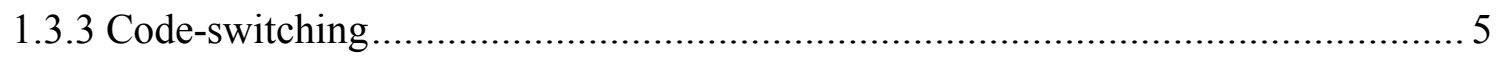

1.4 Human Ethics Requirements........................................................................... 6

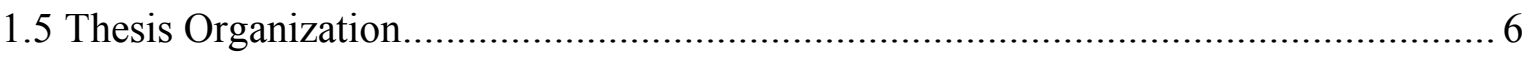

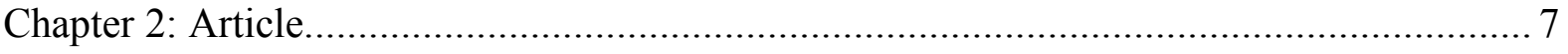

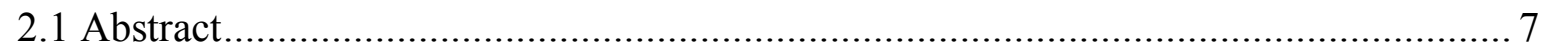

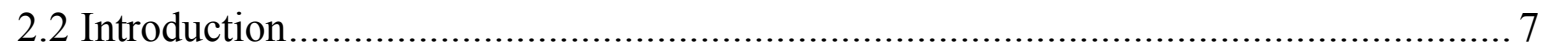

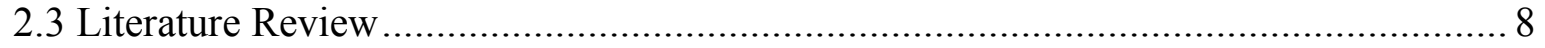

2.3.1 Factors that may Contribute to Incidental Vocabulary Learning ......................... 11

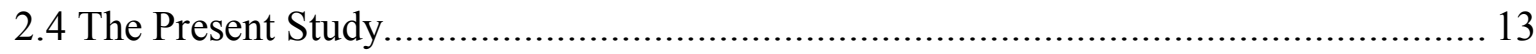




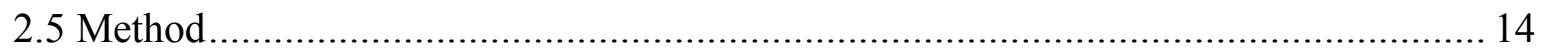

2.5.1 Participants ................................................................................................. 14

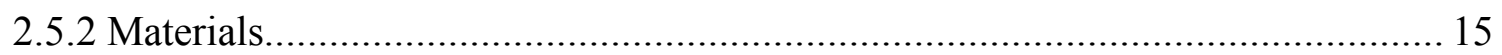

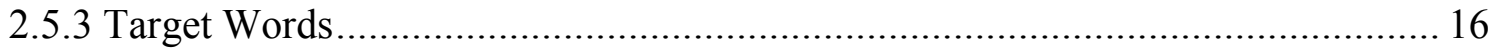

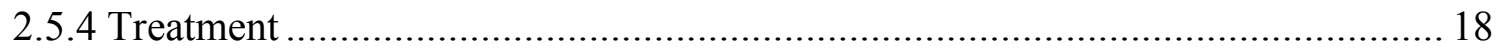

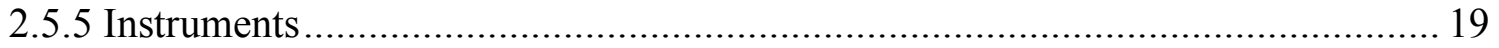

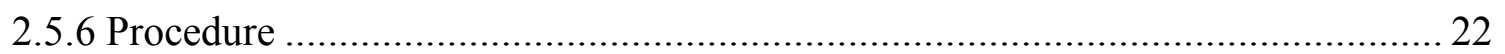

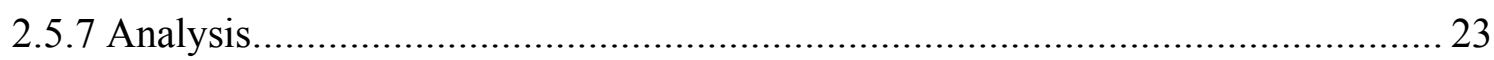

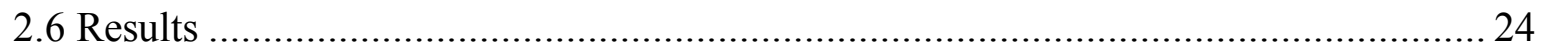

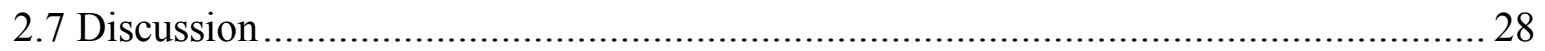

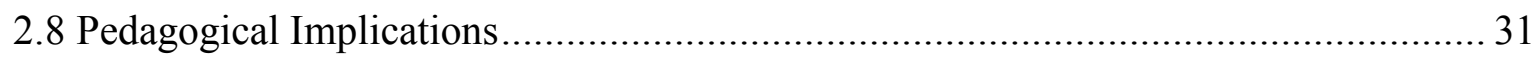

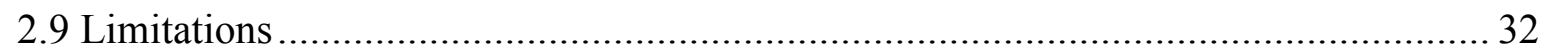

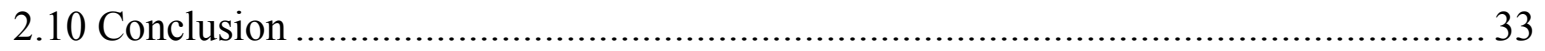

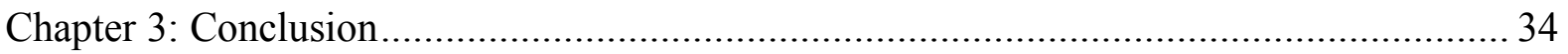

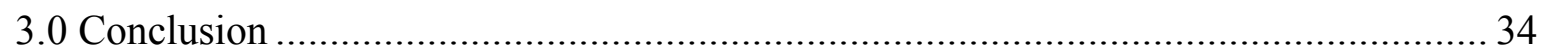

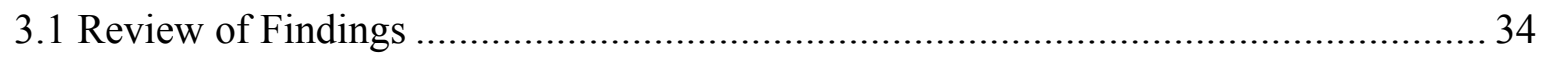

3.2 Implications and Directions for Future Research................................................... 35

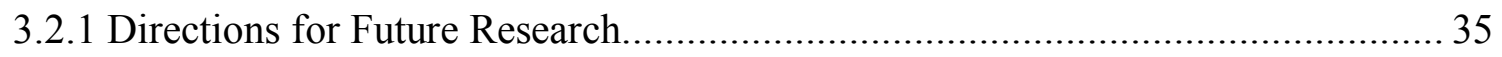

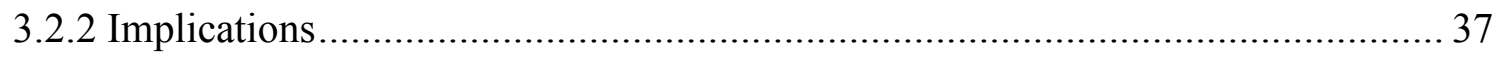

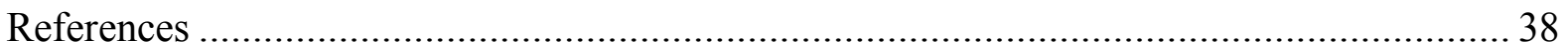

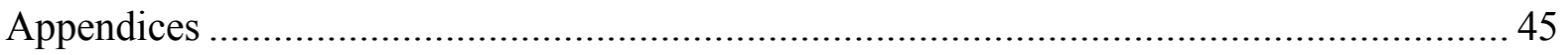

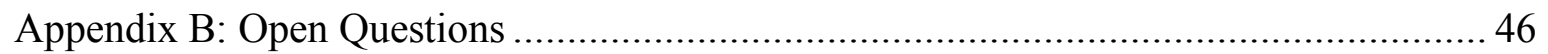




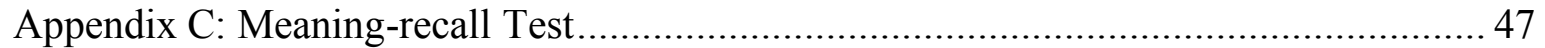

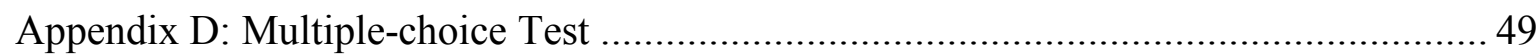

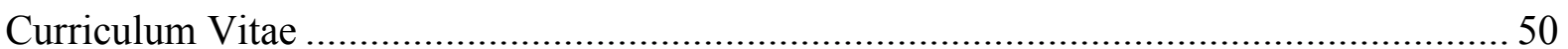




\section{List of Tables}

Table 1 Means and Standard Deviations of the Five Word Frequency Levels 14

Table 2 Target Single Word Items 16

Table 3 Node Word Frequency and Frequency of Occurrence of the Target Collocations ... 17

Table 4 Means and Standard Deviations for Measuring Receptive Knowledge of Single words

Table 5 Means and Standard Deviations for Measuring Receptive Knowledge of Collocation 25

Table 6 Pairwise Comparison for Different Sections of the Tests. 26

Table 7 Logistic Regression for Meaning Recall Test $(N=1434)$..... 28

Table 8 Logistic Regression for Multiple-choice Test $(N=360)$. 28 


\section{List of Appendices}

Appendix A: Ethics Approval Notice ..................................................................... 45

Appendix B: Open Questions .............................................................................................. 46

Appendix C: Meaning-recall Test.............................................................................. 47

Appendix D: Multiple-choice Test ..................................................................... 49 


\section{Chapter 1: Introduction}

\subsection{Thesis Introduction}

This chapter provides a brief introduction of the background, the purpose, the rationale, and the theoretical framework of the present study. The overall structure of this thesis is also stated in this chapter.

\subsection{Background}

Vocabulary is a basic component of language and it is closely related to listening, speaking, reading and writing (Hunt \& Beglar, 2005; Webb \& Nation, 2017). Vocabulary learning is also one of the most important goals in both first and second language classrooms (Nation, 2013; Webb \& Nation, 2017). There are two ways to acquire vocabulary. One is deliberate or intentional vocabulary learning, where the learners' attention is deliberately focused on form or form-meaning connections (Ellis, 1999). The other is incidental vocabulary learning, which is a by-product of the use of language rather than word learning in an intentional way (Ellis, 1999; Webb \& Nation, 2017). Studies on incidental and intentional vocabulary learning show that vocabulary learning is typically greater in more intentionally oriented vocabulary learning contexts (Hunt \& Beglar, 2005; Laufer, 2005), but that most first language (L1) vocabulary is acquired incidentally (Ellis, 1994; Webb \& Nation, 2017).

Incidental vocabulary learning from input is an essential part of second language (L2) vocabulary learning (Krashen, 1989). Vocabulary may often be learned incidentally through written input, particularly from reading (e.g., Hunt \& Beglar, 2005; Krashen, 1989; Waring \& Takaki, 2003), but relatively few studies have investigated incidental vocabulary learning through listening to aural input. Research shows that L1 and L2 words can be learned 
incidentally through listening (Elley, 1989; Vidal, 2011). However, no research has explicitly investigated whether incidental vocabulary learning occurs through listening to teacher talk.

\subsection{Purpose and Rationale}

The present study investigated the extent to which teacher talk contributes to vocabulary learning. English as a foreign language (EFL) students watched a video-taped English language class to determine whether the words spoken by the teacher during the class contributed to incidental vocabulary learning. The main purpose of the study was to investigate whether listening to teacher talk could lead to incidental vocabulary learning of both single-word items and collocations. In order to have a better assessment of learning vocabulary through listening to teacher talk, it is important to measure not only individual words, but also other aspects of vocabulary knowledge, such as collocation. A secondary aim was to investigate the relationship between incidental vocabulary learning and three factors: frequency of occurrence, L1 translation, and writing target words in notes.

There are three reasons why this research is warranted. First, there is no research investigating the extent to which teacher talk might contribute to vocabulary learning. This is surprising because EFL students may have few opportunities to acquire vocabulary outside of the classroom (Webb \& Nation, 2017). Thus, teachers may sometimes be the only people who provide comprehensible spoken input to students (Krashen, 1982), and teacher talk might be the primary source of L2 input (Ellis, 1994). Therefore, it is worth examining the degree to which words might be learned through listening to teachers. Second, investigating the effectiveness of teacher talk on incidental vocabulary learning could potentially show how teachers might contribute to greater foreign or second language vocabulary learning. Currently, the degree to which teacher talk contributes to vocabulary learning is not clear, so this study should help to reveal the extent to which teachers' speech may contribute to 
vocabulary learning. Third, having a better understanding of how variables, such as frequency of occurrence, L1 translation, and note-taking affect vocabulary learning may reveal ways of increasing the lexical growth of EFL students.

Frequency of occurrence has been widely recognized as one of the predictors of vocabulary acquisition (Nation, 2001; Vidal, 2011; Peters \& Webb, 2018), and different modes of input require different numbers of encounters. It is thus useful to look at the relationship between frequency of occurrence and vocabulary learning gains through listening to teacher talk.

In addition, more recent studies tend to accept that conveying meanings through the L1 may be an efficient way to help learners grasp the meanings of L2 words (Cook, 2001; Turnbull \& Dailey-O'Cain, 2009). Because both L1 and L2 languages are often encountered in real EFL classrooms, it is useful to look at how the use of translation in teacher talk may influence learning.

Another factor that may affect learning is the act of note-taking. Because note-taking is common in the classroom (van der Meer, 2012), and writing words is a part of the process of vocabulary learning (Webb \& Piasecki, 2018), it is useful to see how note-taking affects learning. Moreover, allowing participants to take notes should enhance the authenticity of the research.

\subsection{Theoretical Framework}

\subsubsection{Incidental Vocabulary Learning}

Definitions of incidental vocabulary learning vary. Schmitt (1994) defines it as learning vocabulary without any intention to learn it. Consistent with Schmitt (1994), Paribakht and Wesche (1999) hold the view that the extent to which vocabulary is learned incidentally depends on the learners' attentiveness. Tian and Macaro (2012) expand the discussion of 
incidental learning by arguing that learners' attention is focused on the message contained in a text or utterance rather than the form. Ellis (1999), however, argues that these two types of learning cannot be distinguished based solely on 'attention'. He explains that the distinction must, instead, rest on 'focal' and 'peripheral' attention. Intentional learning is usually focused on learning form or form-meaning connections, whereas incidental learning pays focal attention to meaning but allows peripheral attention to other aspects of knowledge. Overall, most researchers regard incidental learning as a by-product of the use of language rather than word learning in an intentional way (Ellis, 1999; Gass, 1999; Schmitt, 2010; Webb \& Nation, 2017).

Considering the vast number of vocabulary items in languages and the limited classroom time for learning words, it is not realistic to teach and learn all words deliberately. Moreover, learners may gain much more knowledge of words when they are encountered in context (e.g., form-meaning connection, collocation, word parts, constraints on use) than when words are learned deliberately in exercises (Webb, 2007; Webb \& Nation, 2017). Therefore, a large portion of vocabulary learning may need to be accomplished through incidental learning (Nation, 2001). In light of the important role incidental learning plays in L2 vocabulary acquisition, this domain has received considerable attention from researchers in the past few decades and guided them for further exploration. However, to date no studies have explicitly investigated incidental vocabulary learning through listening to teacher talk in classroom settings.

\subsubsection{Input Hypothesis (IH)}

Input, in the form of listening and reading, plays an essential role in language learning. In the late 1980s, Krashen introduced the IH into language acquisition (Krashen, 1981). The input hypothesis predicts that in aural and written form, the greater the amount of comprehensible 
input that learners encounter, the more language acquisition that will occur (Krashen,1989). Krashen (1989) provided evidence showing that those who heard more stories tended to write more and use more new words in conversation. Additionally, he found that children who grow up in print-rich environments tend to have a larger vocabulary, which implies that vocabulary size increases with reading. These findings are applicable to both L1 and L2 acquisition. Some researchers have addressed questions on IH (eg., Faltis, 1984; White, 1987), but many recent studies still accept this hypothesis as support for language acquisition and learning (e.g., Brown, Chang, \& Donkaewbua, 2008; VanPatten \& Lee, 2003). Because for EFL learners, teachers may be their main source of comprehensible input (Krashen, 1982), it is of value to investigate incidental vocabulary learning through listening to teacher talk in the EFL classroom context.

\subsubsection{Code-switching}

Code-switching is a phenomenon in bilingual contexts where people have opportunities to communicate in two or more languages in the same conversation (Muysken, 1995). It is also an ability for people to use both the L1 and L2 to communicate rather than to use only one language (Cook, 2001). Teachers using L1 translation in L2 classrooms to explain word meanings can be viewed as involving the process of code-switching to promote learning (Macizo \& Bajo, 2004).

Codeswitching has the potential to be a valuable tool for language learning for several reasons. Firstly, both L1 and L2 are often used in the language classroom, so the use of L1 translation by teachers resembles the patterns of real-life code-switching (Cook, 2001). Secondly, using L1 to convey meanings may be an efficient way to help learners grasp word meanings in the L2 (Webb \& Nation, 2017). Code-switching seems to promote students' cognitive processing, implying that it will help students to learn new vocabulary more 
thoroughly (Lin, 2013). Thirdly, it can create a comfortable and motivated atmosphere in the classroom because learners may find it easier to learn L2 and interact with others when codeswitching is allowed (Cook, 2001). Although there is a debate on the use of L1 by teachers, and earlier teaching methods have tried to avoid the use of L1 for fear that the use of the L1 may hinder L2 learning (Halliwell \& Jones, 1991; Macdonald, 1993), more recent studies have suggested that the L1 may be an efficient way to help learners grasp the meanings of L2 words (Cook, 2001; Turnbull \& Dailey-O'Cain, 2009). Because both L1 and L2 languages are often encountered in real EFL classrooms, it is useful to look at how the use of L1 translation in teacher talk may influence learning.

\subsection{Human Ethics Requirements}

The present study was conducted after obtaining the approval of Western University NonMedical Research Ethics Board. The approval notice is provided in Appendix A.

\subsection{Thesis Organization}

This thesis consists of three parts. Chapter one provides an overview of the present study's background, purpose, rational, theoretical framework, and ethics approval. Chapter two is the integrated article. It presents the quasi-experimental study that investigated incidental vocabulary learning through listening to teacher talk. Chapter three summarizes the findings and implications of the present study and provides suggestions for future research. 


\section{Chapter 2: Article}

\subsection{Abstract}

This study investigated incidental learning of single word items and collocations through listening to teacher talk. Although there are several studies that have investigated incidental vocabulary learning through listening, no research has explicitly investigated the extent to which listening to teacher talk might contribute to vocabulary learning. The present study fills this gap. Additionally, the study explored the relationship between vocabulary learning gains and the following factors: frequency of occurrence, L1 translation, and note-taking. A meaning-recall test and a multiple-choice test were used to evaluate learning gains. The results indicated that (a) teacher talk contributed to vocabulary learning of both single word items and collocations, (b) using L1 translation to explain target word meanings during teacher talk contributed to larger gains on the immediate posttest, (c) writing target words in notes had a positive effect on learning single words but not collocations, and (d) frequency of occurrence did not affect learning.

\subsection{Introduction}

The amount of second language (L2) input that learners encounter plays a large role in determining whether L2 words are learned incidentally (Webb \& Nation, 2017). Classrooms can provide large quantities of L2 input, especially for English as a foreign language (EFL) learners who may not receive an adequate amount of L2 oral or written input outside of the classroom (Webb \& Nation, 2017). For EFL learners, teachers may be their main source of comprehensible input (Krashen, 1982). Most research on L2 incidental vocabulary learning has focused on reading (e.g., Krashen, 1989; Waring \& Takaki, 2003), but surprisingly, few studies have investigated incidental learning of words through listening, especially in the classroom context. Vidal (2011) found that EFL students could learn vocabulary incidentally 
by listening to lectures, and Tian and Macaro (2012) found that the use of the first language (L1) in L2 teacher speech might enhance vocabulary learning in L2 classrooms. However, no research has explicitly investigated the extent to which teacher talk contributes to vocabulary learning.

The current study explores incidental vocabulary acquisition of both single word items and collocations through listening to teacher talk. A secondary aim of the present research was to examine whether the use of L1 translation in teacher talk, writing target words in notes, and frequency of occurrence were associated with increased vocabulary learning. Many studies provide evidence that multiple exposures to a word leads to vocabulary acquisition (eg., Elley, 1989; Webb, Newton, \& Chang, 2013), and research suggests that the elaboration of meaning in spoken and written input positively influences word learning (e.g., Elley, 1989). Furthermore, because note-taking is common in the classroom (van der Meer, 2012), there is great value in examining whether writing words in notes contributes to learning. However, at present there does not appear to be any research that has looked at whether any of these three factors contributes to incidental vocabulary learning through listening to teacher talk.

\subsection{Literature Review}

Incidental vocabulary learning, which is a by-product of encountering meaning-focused input (Gass, 1999; Webb \& Nation, 2017), plays an essential role in both L1 and L2 learning. There are a large number of words to learn, and most L1 words are learned incidentally (Nagy, Herman, \& Anderson, 1985). Moreover, learners may gain much more knowledge of words when they are encountered in context (e.g., form-meaning connection, collocation, word parts, constraints on use) than when words are learned deliberately in exercises (Webb, 2007; Webb \& Nation, 2017). Thus, when words are encountered repeatedly in context, 
learners may not only enrich their vocabulary size, but also enlarge their depth of word knowledge to develop a more complete knowledge of vocabulary.

A large number of L2 studies show that vocabulary can be learned incidentally through reading (e.g., Horst, Cobb, \& Meara, 1998; Waring \& Takaki, 2003). For example, Waring and Takaki (2003) found that after reading the graded reader A Little Princess, L2 learners could recognize the forms of $60 \%$ of the target words, and $40 \%$ of the meanings of the target words on an immediate posttest. In a two-term extensive reading program, Webb and Chang (2015) found that from pretest to immediate posttest, the vocabulary learning gains for EFL learners in Term 1 were $63.18 \%, 44.64 \%$, and $28.12 \%$ in high-, intermediate-, and low-level groups, respectively. They also found that the learning gains in Term 2 were consistent with those in Term 1 . However, relatively little research has investigated incidental vocabulary learning through other types of input.

There are relatively few studies that have investigated L2 incidental vocabulary learning through listening in comparison to reading. Elley (1989) found that reading stories aloud to children helped them to learn new words, and that teachers' explanations of these words increased vocabulary learning. Children who received teacher explanation of word meanings learned $40 \%$ of the words whereas those who did not receive teacher explanations learned $15 \%$ of the words. The study also found that a key predictor of the successful acquisition of a word was the frequency of occurrence of the words in the story. Vidal (2011) compared the effects of listening and reading on incidental vocabulary acquisition and retention of vocabulary. She found that listening contributed to smaller gains $(24 \%)$ in vocabulary knowledge than reading (47\%). Brown et al. (2008) examined the rate at which English vocabulary was acquired by EFL learners through reading, reading-while-listening, and listening to stories. They found that listening-only was the least effective way of learning vocabulary with gains of $29 \%$ on the meaning recognition test and gains of $2 \%$ on the 
meaning-recall test. In contrast, reading while listening contributed to $48 \%$ and $16 \%$ learning gains on the two tests. This rate of acquisition was followed closely in the reading-only mode, which yielded gains of $45 \%$ on the recognition test and $15 \%$ on the recall test.

There is no research investigating incidental vocabulary learning through listening to teacher talk. Teacher talk, the teacher's speech language learners hear in class, is the most fundamental type of input from which to learn new vocabulary (Horst, 2010). Perhaps the reason for the lack of research on teacher talk is that it presents challenges for research because samples of teacher talk tend to be short and discontinuous (Horst, 2010). Although some studies have investigated the potential for vocabulary learning through listening to teacher talk, these studies have involved the analysis of corpora made up of samples of teacher talk rather than investigating learning in a real classroom setting. For example, Meara, Lightbown and Halter (1997) investigated classroom teacher speech by examining which words occurred in the classroom. They found that teacher speech appeared to offer ESL learners more opportunities to hear lower frequency words (words outside of the 2000 most frequent word families and the university word list) in class than they had expected. Meara et al. (1997) found that over the course of a single day, students were exposed to 50 lower frequency words, or 250 lower frequency words in a week. The results showed that teacher talk appeared to be lexically rich and would likely contribute to student vocabulary learning. In a follow up study, Horst (2009) examined a much larger 104,000-word corpus of teacher talk. Her results also suggested that teacher talk may contribute to incidental vocabulary learning. She found that ESL students were exposed to 700 different word families in about 4.5 hours of teacher talk, of which approximately 131 of these items were lower frequency words. In a second study, Horst (2010) examined the extent to which lower frequency words were repeated in a corpus of 121,000 words of teacher talk gathered over 18 successive ESL conversation courses. She reported that incidental vocabulary gains in 
teacher talk were likely to have been minimal, because teachers may not have provided enough repeated exposures of lower frequency words. The corpus-based studies of teacher talk are useful because they indicate that there is the potential to learn lower frequency words through listening to teachers although the amount of learning may be dependent on the extent of repetition with lower frequency words. Horst (2010) found that there were relatively few words that were encountered six or more times in a class. While corpus-based studies provide a useful indication of the potential for learning, intervention studies are necessary to determine the extent to which unknown vocabulary might actually be learned through listening to teacher talk. The present study aims to fill this gap.

Collocations are also likely to be encountered frequently in teacher talk. Research has indicated that $58.6 \%$ of spoken discourse is made up of collocations (Erman \& Warren, 2000 ), and collocations in spoken discourse are $50 \%$ to $100 \%$ more frequent than in written discourse (Shin \& Nation, 2008). However, only a small number of studies have investigated the acquisition of collocation from a classroom-based perspective (e.g., Pellicer-Sánchez, 2017; Webb et al., 2013). Webb et al. (2013) investigated incidental learning of L2 collocations encountered $1,5,10$, and 15 times through reading while listening to a graded reader. They found that collocations were learned incidentally through reading while listening to a graded reader, and that frequency of occurrence had a positive effect on learning of collocations. Similarly, research has also shown that collocations can be learned incidentally through reading (Pellicer-Sánchez, 2017). However, no studies to date have revealed the collocations can be learned incidentally through listening.

\subsubsection{Factors that may Contribute to Incidental Vocabulary Learning}

There are many factors that may affect whether or not words are learned incidentally through spoken input. Frequency of occurrence has been widely recognized as one predictor of 
vocabulary acquisition (Nation, 2001; Vidal, 2011; Peters \& Webb, 2018), and research indicates that different modes of input may require different numbers of encounters for vocabulary learning to occur. Vidal's (2011) results indicated that more exposure to target items may be required for word learning to occur through listening than reading. The greatest vocabulary gains occurred between two and three encounters during reading, whereas the greatest increase occurred when learners heard words five and six times during listening (Vidal, 2011). van Zeeland and Schmitt (2013) suggested that it may take more than 15 encounters to incidentally learn words through listening. They showed that although knowledge of the spoken forms and grammatical function of words could be developed with relatively few exposures (e.g., 7 encounters), more than 15 occurrences appeared to be needed to fully develop and retain this knowledge. Moreover, because knowledge of formmeaning connection seemed particularly unaffected by frequency, van Zeeland and Schmitt (2013) also suggested that listeners may need to encounter words more than 20 times, and perhaps 50 to 100 times to develop the ability to recall a word's meaning.

Another factor that may be positively associated with incidental learning of words through listening to teacher talk, is explanation of word meanings. Webb and Nation (2017) suggest that incidental vocabulary learning is more likely to be successful if teachers deliberately explain word meanings in the L2 classroom. Elley (1989) explored how teacher explanation of L1 word meanings when children listened to stories affected vocabulary learning. He found that teachers' additional explanation of words led to greater vocabulary gains. Lee and Levine (2018) have provided additional evidence that both intermediate and advanced EFL learners who received teacher explanation of target words in L1 during the listening tasks could acquire more vocabulary than learners who did not receive L1 explanation. In addition, teacher explanation of word meanings would help intermediate learners have better retention in the long term. Because both L1 and L2 languages are often 
encountered in real EFL classrooms, it is useful to look at how the use of L1 translation in teacher talk may influence learning.

A third factor that may contribute to incidental vocabulary learning through listening is note-taking. In natural teaching contexts, the act of note-taking is common (van der Meer, 2012). Teachers often encourage students to write down unknown words. Research on word writing has been inconsistent. Several studies indicate that it may contribute to vocabulary learning (Thomas \& Dieter, 1987; Webb \& Piasecki, 2018), while one study suggests that it may reduce vocabulary learning (Barcroft, 2006). No studies have looked at the relationship between note-taking and vocabulary learning, instead focusing on the association between note-taking and listening comprehension (Ahour \& Bargool, 2015), and between note-taking and noticing (Kang, 2010). It is useful to see how note-taking affects learning because writing words is a part of the process of vocabulary learning (Webb \& Piasecki, 2018).

\subsection{The Present Study}

The present study seeks to investigate the effects of listening to teacher talk on incidental learning of single word items and collocations. In addition, it aims to shed light on a number of variables (frequency of occurrence, L1 translation, note-taking) that might influence incidental vocabulary learning through listening to teacher talk. Accordingly, the following research questions were posed:

1. Does listening to teacher talk lead to incidental vocabulary learning of single word items?

2. Does listening to teacher talk lead to incidental vocabulary learning of collocations? 
3. What is the relationship between word learning through listening to teacher talk and the following variables: frequency of occurrence, L1 translation, and note-taking?

\subsection{Method}

\subsubsection{Participants}

A quasi-experimental study was conducted in an EFL context with 140 participants ranging from 18 to 21 in age. The participants were students majoring in English at a university in China, and were considered to be at an advanced English proficiency level within the Chinese EFL context. All participants had been learning English for a minimum of 10 years. They had been randomly assigned by the university to five different classes. These classes were then randomly assigned to experimental or control groups.

The VLT (Webb, Sasao, \& Ballance, 2017) was administered in a paper and pencil format to the participants to determine their prior vocabulary knowledge. The VLT is an updated version of Nation (1983), and Schmitt, Schmitt, \& Clapham's (2001) earlier tests. The VLT provides a measure of vocabulary knowledge at five frequency levels: 1000, 2000, 3000, 4000 and 5000, from Nation's (2012) BNC/COCA word lists. Schmitt et al. (2001) suggest that a score of 26/30 or higher indicates mastery of a VLT level. The participants achieved an average raw score of 82 out of 90 on the first three levels combined, indicating knowledge of approximately 2700 of the most frequent 3,000 words. Table 1 shows the mean scores at each of the five word-frequency levels of the VLT for the two groups.

Table 1 Means and Standard Deviations of the Five Word Frequency Levels

$\begin{array}{lllll}1000 & 2000 & 3000 & 4000 & 5000\end{array}$




\begin{tabular}{lcccccccccc}
\hline Group & $M$ & $S D$ & $M$ & $S D$ & $M$ & $S D$ & $M$ & $S D$ & $M$ & $S D$ \\
Experimental $(n=86)$ & 29.7 & 1.14 & 28.4 & 1.9 & 25.3 & 3.4 & 19.0 & 4.9 & 15.0 & 5.7 \\
Control $(n=54)$ & 29.5 & 1.14 & 26.9 & 2.8 & 23.7 & 4.2 & 17.8 & 5.0 & 13.3 & 5.6 \\
Total $(\mathrm{N}=140)$ & 29.6 & 1.14 & 27.8 & 2.4 & 24.7 & 3.8 & 18.5 & 4.9 & 14.3 & 5.7
\end{tabular}

Note. Maximum score is 30.

\subsubsection{Materials}

The material was a video-taped English language talk given by an experienced English language instructor familiar with the L2 learning context. Using a video-taped talk rather than a live talk ensured that word-related variables were precisely controlled. The talk focused on life experiences both in China and Canada. The instructor spoke as naturally as possible, in the same way that language teachers typically talk to their students in EFL classes at university in China. The video was 26 minutes long and contained 2901 running words. The rate of speech in the video was 112 tokens per minute. Native speakers of English tend to deliver speech at a rate of approximately 170 tokens per minute (Blau, 1990). However, Dunkel (1988) regards 107 words per minute (wpm) as "lecturelike" speed and 165 wpm as "broadcast" speed. As teacher talk was delivered to EFL students, who might have found it hard to comprehend English speech when spoken at a nativelike speed, the rate of speech in the teacher talk was considered to be appropriate.

The spoken text in the video was expected to be comprehensible to the participants. Van Zeeland and Schmitt's (2013) study of incidental vocabulary from listening indicated that $90 \%$ lexical coverage could contribute to adequate L2 listening comprehension. Therefore, in this study, the teacher talk was analyzed using the Range program (Nation \& Heatley, 2002) together with Nation's (2012) British National Corpus/ Corpus of Contemporary American English (BNC/COCA) word family lists. The results of the analysis 
showed that the most frequent 3000 words, plus proper nouns, accounted for $91.29 \%$ coverage of the 2901 words in teacher talk.

\subsubsection{Target Words}

Eighteen single-word items and ten collocations were selected as the target vocabulary. The target single-word items were words that were less frequent than the most frequent 3000 words in Nation's (2012) BNC/COCA lists. The target single-word items were divided into two sets of nine items. The reason for having two sets of target single-word items was to investigate the effects of L1 translation of vocabulary in teacher talk. Thus, for one set of target words, the word meanings were explained in the L1 (Mandarin) during the teacher talk, while for the other set, no translation was provided for the target word meanings. The singleword items in the corresponding two sets had the same frequency of occurrence, and number of letters. Also, each set contained 2 nouns, 3 verbs, and 4 adjectives. The target single-word items are presented in Table 2.

The ten collocations were made up of seven verb-noun collocations and three adjective-noun collocations. All ten items had mutual information scores above three in COCA indicating a statistical strength of co-occurrence typical of collocations. All of the collocations were made up of words from the one to three word-frequency levels in Nation's (2012) BNC/COCA word lists that the participants were likely to know. In a pilot study, the target collocations were found to be unknown to L2 learners with a similar background and learning profile as the participants. The data from the learners in the pilot study was not included in the results. A full list of target collocations is presented in Table 3.

Table 2 Target Single Word Items 


\begin{tabular}{|c|c|c|c|c|c|}
\hline Target Word & $\mathrm{FoO}$ & Translation & Target Word & $\mathrm{FoO}$ & Translation \\
\hline shovel & 9 & 铲子；铲 & frigid & 9 & No \\
\hline hardy & 4 & 吃苦耐劳的 & lousy & 4 & No \\
\hline strenuous & 4 & 艰难的 & ferocious & 4 & No \\
\hline savor & 10 & 享受 & crave & 10 & No \\
\hline blizzard & 7 & 暴风雪 & fabulous & 7 & No \\
\hline persevere & 6 & 坚持 & excursion & 6 & No \\
\hline glum & 5 & 闷闷不乐的 & hiss & 5 & No \\
\hline adept & 3 & 精通的 & elude & 3 & No \\
\hline gravy & 4 & 肉汁 & toque & 4 & No \\
\hline
\end{tabular}

Note. $\mathrm{FoO}=$ frequency of occurrence in the teacher talk

Table 3 Node Word Frequency and Frequency of Occurrence of the Target Collocations

\begin{tabular}{|c|c|c|c|c|}
\hline Frequency & Node & Collocate & $\mathrm{FoO}$ & MI score \\
\hline 1000 & comfort & take & 4 & 4.23 \\
\hline 1000 & talk & small & 4 & 3.97 \\
\hline 1000 & term & long & 4 & 7.38 \\
\hline 2000 & pleasure & feel & 3 & 3.52 \\
\hline 2000 & knowledge & gain & 6 & 3.71 \\
\hline 2000 & research & do & 5 & 3.28 \\
\hline 2000 & feature & important & 6 & 5.03 \\
\hline 3000 & confidence & lose & 4 & 5.58 \\
\hline 3000 & approval & get & 5 & 3.11 \\
\hline 3000 & routine & become & 4 & 4.91 \\
\hline
\end{tabular}


Note. Frequency $=$ frequency level, $\mathrm{FoO}=$ frequency of occurrence in the teacher talk, $\mathrm{MI}$ score $=$ mutual information score

\subsubsection{Treatment}

The treatment for the experimental group was completed over a 40-minute period which included the 26 minutes of the video-taped teacher talk, and approximately 14 minutes of teacher-student interaction. Before watching the video, the participants were told that they had the option of taking notes on a sheet of paper that was provided to them. The teacherstudent interaction began with open questions raised by the teacher, leading to student discussion followed by teacher feedback (the questions are shown in Appendix B). The sequence of the discourse chain (initiation-response-feedback) is a common instructional practice found in EFL classrooms in China (Cullen, 1998). At predetermined times in the teacher talk, the video was stopped and the instructor raised several questions related to the topic, so that teacher-student interaction occurred before, during, and after watching the video. This was done to try to simulate a normal English language class in China. The questions that were asked were easy to discuss and were related to the topics of the video. However, the questions were designed to be unrelated to any of the target words, and unlikely to elicit any of the target vocabulary in the teacher-student interaction. Thus, all target single word and multi-word items were encountered only by the participants during the teacher talk. At the end of the treatment session, all note-taking sheets were collected, and then the participants were given an immediate post-test consisting of a meaning recall test followed by a multiple-choice test in order to examine the effect of teacher talk on vocabulary learning. The control group did not complete the treatment but did complete all tests on the same day.

The target single word items in the video-taped teacher talk were divided into two sets. When words in Set 1 were used by the teacher, she explained the word by providing 
their L1 translations. Whereas when words in Set 2 were spoken, they were not explained by the teacher. For example, during the teacher talk, when the students encountered words in Set 1 such as “hardy”, they also heard its Chinese definition “吃苦耐劳的”. No matter how many times the word was mentioned by the teacher, the target words were only translated two times because it is unnatural for a teacher to translate a target word every time they say it. However, when the participants heard words in Set 2, such as "crave", they were not translated, and the meanings were not explained. The occurrence of the words in the two sets and the collocations were randomly distributed within the 26-minute talk.

All participants in the experimental group were told that the purpose of this study was to investigate listening comprehension so that the participants' attention would be directed to the content of the teacher talk rather than to learning the vocabulary that was encountered in the teacher talk. Informed consent was obtained from all the participants in this study.

\subsubsection{Instruments}

\subsubsection{Meaning Recall Test}

A meaning recall test was used to measure knowledge of form-meaning connection of singleword target items. The test contained 36 items, 18 of which were the target words. The other 18 items were high frequency words from the 1000 and 2000 word levels that the participants were likely to know (See Appendix C). The purpose of including high frequency words was to encourage participants to complete the test. If only the target words were included, the participants may have become discouraged and not taken the tests seriously. However, only the responses for the 18 target items were included in the analysis.

During the test, the participants heard a recording of the words twice, and then wrote down anything they could recall about the meaning of each word in their first language (Mandarin). If they did not know the word meaning, they had the option to check "I don't 
know". The translation could be a synonym, an explanation, a paraphrase, or anything else they could use to demonstrate their knowledge. The participants were given 30 seconds to translate each word. The test was used for the pretest, immediate post-test, and delayed posttest to track and compare the progress of the participants throughout the study. The test items were randomly ordered between test administrations to prevent the participants from remembering the answers by recognizing the order of words.

In the scoring procedure, two different rating scales were initially used: sensitive and strict. The sensitive rating scale allowed measurement of partial vocabulary knowledge. On this scale, 0,1 , and 2 points were awarded to any incorrect, partially correct, and fully correct

response, respectively. For example, responses of 带走(took), 帽子 (a hat), and 冬天的帽子 (a winter hat) for the item toque were awarded 0, 1, and 2 points, respectively. In the strict rating scale, 2 points were awarded for fully correct responses and 0 points were awarded for all other responses. Given that there were 18 target words, the maximum obtainable score was 36 (18 x 2) in both systems. In the above example, only 冬天的帽子 (a winter hat) would have been awarded 2 points in the strict scoring system. Measuring partially and fully correct responses allows a more accurate assessment of potential learning gains than measuring only fully correct responses (Webb, 2008). However, the analyses revealed that both scoring methods produced similar findings; all results that were statistically significant with sensitive scoring were also statistically significant with strict scoring. Therefore, only the results with strict scoring will be reported.

\subsubsection{Multiple-choice Test}

A multiple-choice test was used to measure receptive knowledge of collocation. The test was designed to measure knowledge of the 10 target collocations and 10 high frequency collocations that the participants were expected to know (See Appendix D). Only responses 
for the 10 target items were included in the analysis. The items for the target collocations were taken from Nguyen and Webb's (2017) Receptive Knowledge of Collocation test. The test items were randomly ordered between the pretest, immediate post-test, and delayed posttest. One key, three distractors, and an "I don't know" option were provided for each item. The participants listened to the recording of the test with the node words orally presented along with the five options (key, distractors, I don't know). They were instructed to circle the correct collocate from among the four choices. The options for the target items take comfort and small talk are shown below.

The participants hear:

'Number one, comfort [1 sec.] A, take comfort [2 sec.] B, lose comfort [2 sec.] C, make comfort [2 sec] D, put comfort [2 sec] (then this sequence is repeated)

Number four, talk [1 sec.] A, clear talk [2 sec.] B, close talk [2 sec.] C, pretty talk [2 sec] D, small talk [2 sec] (then this sequence is repeated)'

The participant sees on paper:
1. A. take
B. lose
C. make
D. put
I don't know
4. A. clear
B. close
C. pretty
D. small
I don't know

All data in this test were scored dichotomously with one marked for a correct response and zero for an incorrect response.

\subsubsection{Note-taking Assessment}

The participants had the option of taking notes during the treatment. Because there was no requirement to take notes, and the participants were unaware of the focus on vocabulary in the study, the contents of the notes varied to a large degree. Some participants did not take 
any notes, some participants did include some target words in their notes, and some participants took notes that did not include any target words. The note-taking variable in the present study only focused on notes that included the target words.

In order to examine the relationship between note-taking and vocabulary learning of target word items, two scoring systems were used. One was for correct spellings; the other was for partially correct and correct spellings. However, the results for these two scoring systems were also found to be statistically equivalent, and so only the results for correct spellings will be presented. Thus, when the participants wrote down the correct spellings of any target words or their meanings, the target word was scored as written in notes. For example, for the item toque, any vocabulary written such as hat, or toque were scored as written in notes.

\subsubsection{Procedure}

In the first week, all of the participants completed the VLT (Webb et al., 2017) followed by the pretest which was made up of the meaning recall test followed by the multiple-choice test. This session lasted approximately 70 minutes. Then the participants were randomly assigned to either the experimental or control group. One week later, participants in the experimental group completed the treatment and the immediate posttest. Participants in the control group only completed the immediate posttest.

One week after the treatment, all participants took a delayed posttest that was made up of the meaning recall test followed by the multiple-choice test to investigate retention of the target words. Participants were given sufficient time to complete all tests. After the delayed posttest, all participants received a debriefing to clarify the real purpose of this study. This session lasted approximately 40 minutes. 


\subsubsection{Analysis}

SPSS (Version 23) was used to analyse the data. The data from the participants who missed any of the testing sessions (pretest, immediate post-test, and delayed post-test) were excluded from analysis. To answer the first research question, a repeated measures ANOVA was conducted with test timing as the within-participants variable (pretest vs. posttest vs. delayed), and treatment as the between-participants variable (experimental vs. control). A follow-up pairwise comparison was carried out to examine the mean difference within each group at each testing time and the mean difference between the experimental and control groups at the three test time points.

To answer the second research question, a repeated-measures analysis of covariance (ANCOVA) was used to assess whether mean differences existed on multiple choice test scores at different testing times after controlling for each participant's pretest scores. Multiple-choice test scores were used as dependent variables, treatment as the betweenparticipants variable (experimental vs. control), and the pretest score as the covariate to adjust for any pre-existing differences of each participant's pretest score on their knowledge of collocation in this study.

To answer the third research question, a multiple logistic regression was conducted to determine which variables explained the learning gains in the posttests. The analysis is based on the number of cases and not on total test scores or total learning gains per participant. This means that the combination "participant, item, response" defines for each observation a particular score (correct/incorrect) on a particular item for a particular participant. For each parameter, the odds ratio is calculated that predicts the odds of a correct response. Because only single word items received L1 translation, analyses were conducted for single word items and collocations, separately. The following parameters were included in the model for 
single word items: frequency of occurrence, L1 translation, and note-taking; frequency of occurrence, and note-taking were included in the model for collocations.

\subsection{Results}

Descriptive statistics of the meaning recall test at the three test time points are presented in Table 4. Results showed that from pretest to posttest, both the experimental and control groups' mean scores increased. To determine whether there were any differences within each group (experimental and control) at different times of testing (pretest, immediate posttest, and delayed posttest), and whether there were differences between the groups at each time of testing, a repeated measures ANOVA was conducted.

Table 4 Means and Standard Deviations for Measuring Receptive Knowledge of Single Words

\begin{tabular}{lccccccc}
\hline & \multicolumn{3}{c}{ Pretest } & \multicolumn{2}{c}{ Posttest } & \multicolumn{2}{c}{ Delayed posttest } \\
\cline { 2 - 8 } & $n$ & $M$ & $S D$ & $M$ & $S D$ & $M$ & $S D$ \\
\hline Experimental & 86 & 2.35 & 3.78 & 8.05 & 5.75 & 6.23 & 5.85 \\
Control & 54 & 2.26 & 3.67 & 3.81 & 4.33 & 3.44 & 4.03 \\
\hline
\end{tabular}

Note. Maximum score is 36.

The ANOVA for receptive vocabulary knowledge of single word items revealed significant effects for learning condition, $F(2,137)=13.571, p<.001$, partial $\eta^{2}=0.165$, and for testing time, $F(2,137)=41.923, p<.001$, partial $\eta^{2}=0.380$. Significant interaction between learning condition and testing time was also found, $F(1.817,250.724)=17.530, p<$ $.001, \eta^{2}=0.113$. The pairwise comparison between pretest and posttest on the meaning recall test indicated that there was a significant increase between pretest and posttest and between 
pretest and delayed posttest for both the control $(p=0.013, d=.167$ and $p=0.04, d=.110$, respectively) and the experimental group $(p<.001, d=.557$ and $p<.001, d=.416$, respectively). The pairwise comparisons between pretest and immediate posttest scores and pretest to delayed post test scores are shown in Table 6.

Testing the simple main effect of treatment group showed that there was no significant difference in the pretest scores between the experimental and control groups $(p=$ .890). However, the experimental group scored significantly higher on the posttest $(p<.001)$ and delayed posttest $(p=0.003)$ than the control group, indicating that vocabulary learning could be attributed to listening to teacher talk.

Descriptive statistics of the multiple-choice test at the three test time points are presented in Table 5. The mean scores for the experimental group increased from 5.81 to 6.67 whereas the mean scores for the control group decreased from 5.28 to 5.15. The delayed posttest scores for both groups increased from pretest to delayed posttest.

Table 5 Means and Standard Deviations for Measuring Receptive Knowledge of Collocation

\begin{tabular}{lccccccc}
\hline \multirow{2}{*}{ Group } & \multicolumn{3}{c}{ Pretest } & \multicolumn{2}{c}{ Posttest } & \multicolumn{2}{c}{ Delayed posttest } \\
\cline { 2 - 8 } & $n$ & $M$ & $S D$ & $M$ & $S D$ & $M$ & $S D$ \\
\hline Experimental & 86 & 5.81 & 1.18 & 6.67 & 1.62 & 6.44 & 1.47 \\
Control & 54 & 5.28 & 1.35 & 5.15 & 1.31 & 5.33 & 1.32 \\
\hline
\end{tabular}

Note. Maximum score is 10.

An ANCOVA revealed that there were significant effects for learning condition, $F(1$, $136)=9.006, p<.001, \eta^{2}=0.117$, and for testing time, $F(2,136)=9.937, p<.001, \eta^{2}=$ 0.127. Significant interaction was also found, $F(2,274)=9.714, p<.001, \eta^{2}=0.066$. The pairwise comparison between pretest and posttest on the multiple-choice test indicated that 
there was a significant increase between pretest and posttest $(p<.001)$ with a small effect size $(d=0.049)$ and between pretest and delayed posttest $(p<.001)$ with a small effect size $(d=0.025)$ for the experimental group. No significant difference was found between pretest and posttest and between pretest and delayed posttest for the control group. These pairwise comparisons are shown in Table 6.

Table 6 Pairwise Comparison for Different Sections of the Tests

\begin{tabular}{|c|c|c|c|c|c|}
\hline $\begin{array}{l}\text { Time of } \\
\text { Testing }(i)\end{array}$ & $\begin{array}{l}\text { Time of } \\
\text { Testing }(j)\end{array}$ & $\begin{array}{l}\text { Difference } \\
\text { between } \\
\text { means }(j-i)\end{array}$ & $S E$ & $p$ & $\begin{array}{l}95 \% \text { confidence interval for th } \\
\text { difference }\end{array}$ \\
\hline
\end{tabular}

Upper bound Lower bound

MR Experimental

\begin{tabular}{|c|c|c|c|c|}
\hline 2 & $-5.698^{*}$ & .482 & .000 & -6.671 \\
\hline 3 & $-3.884 *$ & .453 & .000 & -4.779 \\
\hline
\end{tabular}

MR Control

$\begin{array}{rrrrrr}2 & -1.556^{*} & .621 & .013 & -2.783 & -.328 \\ 3 & -1.185^{*} & .571 & .040 & -2.315 & -.056\end{array}$

MC Experimental

$\begin{array}{llllll}2 & -.924^{*} & .169 & .000 & -1.258 & -.589 \\ 3 & -.675^{*} & .157 & .000 & -.986 & -.364\end{array}$

MC Control

$\begin{array}{lllllll}1 & 2 & .230 & .214 & .284 & -.193 & .643 \\ & 3 & .020 & .199 & .921 & -.373 & .413\end{array}$

Note. ${ }^{*}$ indicates $p<.05, \mathrm{MR}=$ Meaning recall test, $\mathrm{MC}=$ multiple-choice test 
A multiple logistic regression was carried out with the data from the immediate posttest and delayed posttest on both meaning recall test and multiple-choice test for the experimental group to determine the relationship between learning gains and several variables (frequency of occurrence, L1 translation, and note-taking for single word items; frequency of occurrence and note-taking for collocations). Responses for the 18 target single word items and 10 target collocations were examined. The words that the 86 participants in the experimental group already knew before the treatment were excluded. Therefore, if a response for a test item was incorrect for a participant in the pretest, then this item was not known and could potentially be learned. The analysis in total was computed for 1794 observations, indicating that there were 1794 items that the participants did not know before the treatment and could potentially be learned. Among the 1794 observations, 1434 were single words and 360 were collocations.

The analysis revealed that two parameters contributed significantly to the model for single-word items in the immediate posttest: L1 translation and note-taking (see Table 7). For each of these two variables, there was a positive relationship with word learning. However, only note-taking contributed significantly to single-word retention in the delayed posttest (See Table 7). Frequency of occurrence did not contribute significantly to word learning or retention. The odds ratio values showed the following:

1. When a target word was translated during teacher talk, the odds of a correct response were $81.3 \%$ higher in the immediate posttest. However, L1 translation did not contribute significantly to word retention in the delayed posttest.

2. Words written in notes were 14 times more likely to be learned than words that were not written in notes in the immediate posttest. Whereas in the delayed posttest, words written in notes were 9 times more likely to be retained than those that were not written in notes. 
Table 7 Logistic Regression for Meaning Recall Test $(N=1434)$

\begin{tabular}{lllllll}
\hline & \multicolumn{5}{l}{ Immediate posttest } & \multicolumn{5}{l}{ Delayed posttest } \\
\cline { 2 - 6 } Parameter & $S E$ & Odds ratio & $p$ & $S E$ & Odds ratio & $p$ \\
\hline FoO & .030 & 1.035 & .256 & .034 & 1.057 & .102 \\
L1 Translation & .145 & 1.813 & $<.001$ & .163 & 1.313 & .096 \\
Note-taking & .316 & 15.023 & $<.001$ & .277 & 10.184 & $<.001$ \\
\hline
\end{tabular}

Note. $\mathrm{FoO}=$ frequency of occurrence.

The analysis, which was run for collocations had 360 observations (= items unknown on the pretest). The results showed that neither frequency of occurrence nor note-taking had a significant or positive correlation with the immediate posttest and delayed posttest (see Table 8).

Table 8 Logistic Regression for Multiple-choice Test $(N=360)$

\begin{tabular}{llllllll}
\hline & \multicolumn{5}{l}{ Immediate posttest } & \multicolumn{5}{l}{ Delayed posttest } \\
\cline { 2 - 7 } Parameter & $S E$ & Odds ratio & $p$ & $S E$ & Odds ratio & $p$ \\
\hline FoO & .113 & 1.142 & .238 & .118 & .962 & .743 \\
Note-taking & 15191.515 & $2.559 \mathrm{E}+9$ & .999 & 15191.515 & $3.171 \mathrm{E}+9$ & .999 \\
\hline
\end{tabular}

Note. $\mathrm{FoO}=$ frequency of occurrence

\subsection{Discussion}

In answer to the first research question, the results indicated that participants in the experimental group had significantly larger gains in the posttest (16\%) and delayed posttest (11\%) than those in the control group (4.5\% in the posttest, and 3\% in the delayed posttest). The findings provide evidence that teacher talk contributes to L2 incidental vocabulary 
learning of single word items. This is useful because it suggests that the meaning-focused speech that students encounter in the classroom is another source of incidental vocabulary learning. These results expand on those of earlier studies that have shown that reading (Horst et al., 1998; Waring \& Takaki, 2003), listening (Vidal, 2003; van Zeeland \& Schmitt, 2013), reading while listening (Brown et al., 2008; Webb \& Chang, 2012), and viewing (Peters \& Webb, 2018; Rodgers, 2013) contribute to L2 incidental learning of single-word items. Although the results revealed relatively small learning gains, teacher talk in the current study only lasted 26 minutes representing a very small proportion of the spoken (and written) input that students encounter in the classroom. It is thus important to note that incidental vocabulary gains tend to occur in small increments and greater learning would likely occur if learners were exposed to larger quantities of input with further exposures to items (Webb \& Nation, 2017).

In answer to the second research question, the results indicated that listening to teacher talk contributed to incidental learning of collocation. Earlier research has shown that reading (Pellicer-Sánchez, 2017) and reading-while-listening (Webb et al., 2013) contribute to incidental learning of L2 collocations. The present study builds on these findings by providing evidence that collocations may also be learned incidentally in the classroom through listening to teacher talk.

In answer to the third research question, the results showed that L1 translation and note-taking were significantly associated with incidental vocabulary learning of single word items in the immediate posttest, whereas in the delayed posttest, only note-taking was a predictor of learning. However, no significant effect was found for note taking on incidental learning of collocation, and, there was no relationship between frequency of occurrence and learning single word items and collocations. 
Of the three variables investigated for single word items, note-taking was the factor that had the largest effect on learning. The odds that the meanings of individual words that were written in notes could be recalled were 14 times higher immediately after the treatment and 9 times higher a week later than for words that were not written in notes. Thus, the findings showed that participants had considerably better learning of target words that were written in notes, which supports earlier studies indicating that word writing contributes to learning (Thomas \& Dieter, 1987; Webb \& Piasecki, 2018). In contrast, note-taking did not appear to contribute to learning collocations. However, this was likely due to the small number of collocations that students wrote in notes. The number of target collocations students wrote in notes was much smaller than it was for unknown single words that they wrote in notes ( 7 and 61 , respectively). This may be because the learners were less likely to attend to the unknown target collocations than the unknown single-word items. Learner's attention may have been focused more on learning the unfamiliar target single words rather than the target collocations that were made up of high-frequency words that they were likely to know. This might suggest that learners' attention is drawn to novel L2 vocabulary when listening to spoken input rather than to familiar words.

The results also revealed a positive relationship between teacher explanation using L1 translation and vocabulary learning in the immediate posttest but not in the delayed posttest for single word items. This suggests that the use of L1 translations to convey meanings in teacher talk increases the likelihood that L2 words will be learned incidentally. Providing L1 translations for unknown words might make these items more salient and also reduce the chance that these words will be incorrectly guessed. This finding is supported by studies of reading-while-listening that have shown that when teachers elaborate on the meanings of unknown words encountered in stories that were read aloud, it enhanced vocabulary learning gains (Elley, 1989; Biemiller \& Boote, 2006). Although L1 translation did not lead to a 
significant effect in the delayed posttest, this does not mean L1 translation does not have value. There will typically be decay of vocabulary knowledge if words that are learned incidentally are not encountered further (e.g., Waring \& Takaki, 2003). However, in the language learning classroom there will typically be an effort made by teachers and materials designers to recycle target vocabulary. An initial boost in vocabulary knowledge may have great value if words are encountered further in materials or teacher speech.

One unanticipated finding was the lack of a relationship between frequency of occurrence and vocabulary learning. This contrasts many earlier studies that have revealed frequency of occurrence to have a positive impact on L2 vocabulary learning (e.g., van Zeeland \& Schmitt, 2013; Vidal, 2003). There are two possible explanations for this finding. First, the number of encounters with target items in this study may have been insufficient. Research indicates that learners may need to encounter unknown single words 10 times (Webb, 2007) and collocation 15 times (Webb et al., 2013) for sizable learning gains to occur. However, in this study, only two target words (savor and crave) were encountered 10 times, and most items in the teacher talk were only encountered around 4 times. Second, within this study the effects of note-taking and L1 translation may have reduced the contributions of frequency on vocabulary learning. Because of the large amount of research indicating that frequency of occurrence typically leads to learning, it would be useful to further investigate its contribution to incidental vocabulary learning through listening to teacher speech in follow-up studies.

\subsection{Pedagogical Implications}

The present study clearly indicates that there is the potential for teacher talk to contribute to L2 lexical development. This suggests that teachers should create opportunities to regularly include target single words and collocations in their speech to further help their students learn 
vocabulary incidentally. Although there has been suggestion that L2 teachers should not use the L1 in the classroom, the findings indicate that elaborating on word meanings using L1 translations in the classroom is beneficial. The positive relationship between L1 translation and learning gains in the immediate posttest suggests that it may be a very efficient way of boosting learning gains in the short term. However, the results showing that L1 translation had no relationship with learning gains in the delayed posttest suggests that teachers need to recycle target words frequently in spoken and written input, or have students use words so that knowledge of target words may be consolidated.

In terms of note-taking, its positive effects on learning suggest that students should be taught to write down the unknown words that they encounter in teacher speech as this will likely enhance learning. However, because the number of target words written in notes was relatively small, it may be necessary for teachers to help learners develop the habit of writing down unknown words in their notes. Moreover, these words should not only be limited to single word items, but should also include formulaic language. Activities could be designed to encourage students to write down unknown target words and teachers could review the extent to which this is done. This might be done by providing partial notes or notes with blanks and asking students to fill in blanks while listening to teacher talk (van der Meer, 2012).

\subsection{Limitations}

Several limitations of the current study should be considered. First, it should be noted that teacher talk was limited to only 26 minutes in this study. This is likely a small proportion of teacher speech that many L2 learners encounter per week. Moreover, the recorded teacher talk examined in this study may not be representative of many teacher-student interactions. In this study, the teacher talk consisted of segments of monologue separated by short dialogue 
with students to better control for the different variables examined in the study. It would thus be useful to examine how different types of teacher student interactions and different amounts of teacher talk contribute to learning.

A second limitation is that because note-taking is a spontaneous behavior, students may or may not choose to write words in notes. In this study, if each participant had written every unknown target word in their notes, there would have been 1794 observations of note taking. However, only 68 target words were actually written in notes. It is thus unclear whether similar learning gains would occur with a larger proportion of unknown words written in notes. Because this is the first study to examine the effects of writing words in notes on vocabulary learning when listening to teacher talk, further research on this topic is warranted.

\subsection{Conclusion}

The present study indicated that teacher talk contributes to incidental vocabulary learning of both individual words and collocations, and that L1 translation of unknown word meanings in teacher speech and writing words in notes may enhance learning gains for single word items. Because this is the first study to investigate the effects of teacher talk on vocabulary learning, it would be useful to further explore this topic. In particular, it would be useful to examine how different types of teacher student interactions contribute to learning. Also, it would be useful to look at the development of productive knowledge of single and multiword items through listening to teacher talk. 


\section{Chapter 3: Conclusion}

\subsection{Conclusion}

This chapter provides an overview of the findings of the present study. Implications and directions for future research that were not discussed previously were summarized in this chapter.

\subsection{Review of Findings}

Vocabulary learning from listening to teacher talk. Overall vocabulary gains of $15.8 \%$ for single word items and $8.6 \%$ for collocations were found for the experimental group from pretest to immediate posttest. In contrast, the control group showed a gain of $4.3 \%$ for single word items and a decrease of $1.3 \%$ for collocations from pretest to immediate posttest. Although there was a significant increase in learning single word items for both the experimental and the control group, the experimental group scored significantly higher on the immediate posttest than the control group. Therefore, listening to teacher talk could contribute to incidental vocabulary learning of both single word items and collocations.

L1 translation and vocabulary gains. The investigation of the relationship between L1 translation and vocabulary gains indicated that when a target word was translated during teacher talk, students' correct response in form-meaning connection of single words was $81.3 \%$ higher in the immediate posttest. No significant relationship was found in the delayed postest.

Note-taking and vocabulary gains. A significant relationship was found between notetaking and vocabulary gains for single word items. Words written in notes were 14 times more likely to be learned than words that were not written in notes in the immediate posttest. Whereas in the delayed posttest, words written in notes were 9 times more likely to be 
retained than those that were not written in notes. However, note-taking did not appear to contribute to learning collocations.

Frequency of occurrence and vocabulary gain. The study did not find any relationship between frequency of occurrence and vocabulary learning.

\subsection{Implications and Directions for Future Research}

Major implications and directions for future research were discussed in the previous chapter. Nevertheless, to further emphasize the importance of the findings in this study and how they can lead the way for further research in the field of second or foreign language learning, this section will discuss further implications and directions for future research that were not discussed previously.

\subsubsection{Directions for Future Research}

Although this study provided some insight into the development of vocabulary learning through listening to teacher talk, there are still several suggestions for further research in this area. For example, this study looked at the relationships between three variables, frequency of occurrence, L1 translation, and note-taking and the incidental vocabulary learning of advanced EFL learners from listening to teacher talk. It would also be useful in future studies to examine learner factors, for example, prior vocabulary knowledge, on vocabulary learning. Because prior vocabulary knowledge is a factor that affects vocabulary learning from reading (Webb \& Chang, 2015) and viewing (Rodgers, 2013), there is no study investigating the relationship between prior vocabulary knowledge and vocabulary learning through listening to teacher talk. The present study did not include prior vocabulary knowledge as a factor because all the participants were first-year English majors, and around 83 percent of them were at the 2000 and 3000 word level. The relationship between prior vocabulary knowledge 
and vocabulary learning would be better investigated if the participants are in different vocabulary levels, and they can be assigned to several groups in a relatively equal number according to their test scores.

Another limitation was that the participants in this study were similar in terms of age group, gender and L2 learning background. They were all advanced EFL learners in China ranging from 18 to 21 in age, and no more than 10 were male students among 140 participants. The findings of this study may not be generalizable to other age groups, or those from more male learners, and mixed language learning backgrounds. Given that this was the first study to look at incidental vocabulary learning from listening to teacher talk in an EFL context, future studies could investigate different types of populations in different contexts to provide a more accurate assessment of learning. For example, it could be explored whether differences in age group and L2 proficiency levels have any effects on vocabulary learning from listening to teacher talk.

A third limitation in this study that should be considered in future research can be drawn from the criterion of unknown word items designed to assure the learning gains. In the present study, we assume that if a response for a test item was incorrect for a participant in the pretest, then this item was not known and could potentially be learned. Although this criterion was used in this study as well as in other research (e.g., Peters \& Webb, 2018), the number of unknown words may be underestimated. We can assume that any word which was incorrect in the pretest was unfamiliar to the participant, however, we cannot exclude the possibility that the correct response for a test item in the pretest was from guessing, especially in the multiple-choice test. For example, if a participant's response to a target word was correct in the pretest, but not correct in the posttest, this word item may also be an unknown word, and should be included in the data set. Therefore, some words may be 
overestimated as known words when conducting multiple logistic regression. A more strict and generalizable assessment of learning gains need to be modified in future research.

\subsubsection{Implications}

As was discussed earlier, this study was the first to investigate incidental vocabulary learning through listening to teacher talk in a real classroom setting. It provided evidence that listening to teacher talk, as a source of language input, could positively affect EFL learners' vocabulary acquisition. The study may also raise awareness of the factors that can influence the level of teaching and learning success when listening to teacher talk in the classroom and may shed light on the use of learning strategies and activities to fuel L2 incidental acquisition in classroom settings. 


\section{References}

Ahour, T., \& Bargool, S. (2015). A comparative study on the effects of while listening note taking and post listening summary writing on iranian EFL learners' listening comprehension. Theory and Practice in Language Studies, 5(11), 2327.

Barcroft, J. (2004). Effects of sentence writing in second language lexical acquisition. Second Language Research, 20(4), 303-334.

Biemiller, A., \& Boote, C. (2006). An effective method for building meaning vocabulary in primary grades. Journal of Educational Psychology, 98(1), 44-62.

Blau, E. K. (1990). The effect of syntax, speed, and pauses on listening comprehension. TESOL Quarterly, 24(4), 746-753.

Brown, R., Waring, R., \& Donkaewbua, S. (2008). Incidental vocabulary acquisition from reading, reading-while-listening, and listening to stories. Reading in a Foreign Language, 20, 136-163.

Cook, V. (2001). Using the first language in the classroom. Canadian Modern Language Review, 57(3), 402-423.

Cullen, R. (1998). Teacher talk and the classroom context. ELT Journal, 52(3), 179-187.

Dunkel, P. (1988). The effect of delivery modification on notetaking and comprehension of L2 lectures. Journal of Intensive English Programs, 2, 41-52.

Elley, W. B. (1989). Vocabulary acquisition from listening to stories. Reading Research Quarterly, 24(2), 174-187.

Ellis, N. C. (1994). Implicit and explicit learning of languages. London; San Diego: Academic Press.

Ellis, R. (1999). Learning a second language through interaction. Amsterdam: John, Benjamins. 
Erman, B., \& Warren, B. (2000). The idiom principle and the open choice principle. Text, 20, $29-62$.

Faltis, C. (1984). A commentary on krashen's input hypothesis. TESOL Quarterly, 18(2), $352-357$.

Gass, S. (1999). Discussion: Incidental vocabulary learning. Studies in Second Language Acquisition, 21(2), 319-333.

Halliwell, S., \& Jones, B. (1991). On target: Teaching in the target language. London: CILTR.

Horst, M., Cobb, T., \& Meara, P.M. (1998). Beyond a clockwork orange: acquiring second language vocabulary through reading. Reading in a Foreign Language, 11(2), 207223.

Horst, M. (2009). Revisiting classrooms as lexical environments. In T. Fitzpatrick \& A. Barfield (Eds.), Lexical processing in second language learners: Papers and perspectives in honour of Paul Meara (pp. 53-66). Clevedon, England: Multilingual Matters.

Horst, H. (2010). How well does teacher talk support incidental vocabulary acquisition? Reading in a Foreign Language, 22(1), 161.

Hunt, A., \& Beglar, D. (2005). A framework for developing EFL reading vocabulary. Reading in a Foreign Language, 17(1), 23.

Kang, E.Y. (2010). Effects of output and note-taking on noticing and interlanguage development. TESOL and Applied Linguistics, 10(2). 19-36.

Krashen, S. D. (1981). Second language acquisition and second language learning (1st ed.). Oxford; Toronto;: Pergamon Press. 
Krashen, S. D., \& Pergamon Institute of English (New York, N.Y.). (1982). Principles and practice in second language acquisition (1st ed.). Oxford; New York: Pergamon Press.

Krashen, S. (1989). We acquire vocabulary and spelling by reading: Additional evidence for the input hypothesis. The Modern Language Journal, 73(4), 440-464.

Laufer, B. (2005). Focus on form in second language vocabulary learning. In S. Cohen, M. Mayo, \& J. Cenoz (Eds.), Eurosla Yearbook (pp.223-250).

Lee, J. H., \& Levine, G. S. (2018). The effects of instructor language choice on second language vocabulary learning and listening comprehension. Language Teaching Research, 136216881877091.

Lin, A. (2013). Classroom code-switching: Three decades of research. Applied Linguistics Review, 4(1), 195-218

Macdonald, D. (1993). Learners and modified/negotiated interactions: what works for pronunciation. Language Learning, 32, 201-227.

Macizo, P., \& Bajo, M. T. (2004). When translation makes the difference: Sentence processing in reading and translation. Psicologica, 25(2), 181.

Meara, P., Lightbown, P. M., \& Halter, R. H. (1997). Classrooms as lexical environments. Language Teaching Research, 1, 28-47.

Muysken, P. (1995). Code-switching and grammatical theory. In L. Milroy \& P. Muysken (Eds.), One Speaker, Two Languages: Cross-disciplinary Perspectives on Codeswitching (pp. 177-197). New York, Cambridge University Press.

Nagy, W. E., Herman, P. A., \& Anderson, R. C. (1985). Learning words from context. Reading Research Quarterly, 20(2), 233-253. 
Nation, I. S. P. (1983). Testing and teaching vocabulary. Guidelines, 5(1), 12-25. Retrieved from http://www.victoria.ac.nz/lals/about/staff/publications/paul-nation/1983-Testingand-teaching.pdf

Nation, I. S. P. (2001). Learning vocabulary in another language. New York: Cambridge University Press.

Nation, I.S.P., \& Heatley, A. (2002). Range: A program for the analysis of vocabulary in texts [software]. Downloadable from http://www.vuw.ac.nz/lals/staff/paulnation/nation.aspx

Nation, I. S. P. (2012). The BNC/COCA word family lists. Retrieved from https://www.victoria.ac.nz/lals/about/staff/paul-nation\#vocab-programs

Nation, I. S. P. (2013). Learning vocabulary in another language (2nd eds.). New York, NY: Cambridge University press.

Nguyen, T. M. H., \& Webb, S. (2017). Examining second language receptive knowledge of collocation and factors that affect learning. Language Teaching Research, 21(3), 298320.

Paribakht, T. S., \& Wesche, M. (1999). Reading and "incidental" 12 vocabulary acquisition. Studies in Second Language Acquisition, 21(2), 195-224

Pellicer-Sánchez, A., \& Schmitt, N. (2010). Incidental vocabulary acquisition from an authentic novel: Do things fall apart? Reading in a Foreign Language, 22(1), 31.

Pellicer-Sánchez, A. (2017). Learning L2 collocations incidentally from reading. Language Teaching Research, 21(3), 381-402.

Peters, E., \& Webb, S. (2018). Incidental vocabulary acquisition through viewing L2 television and factors that affect learning. Studies in Second Language Acquisition. Advance online publication. 
Rodgers, M.P.H. (2013). English language learning through viewing television: An investigation of comprehension, incidental vocabulary acquisition, lexical coverage, attitudes, and captions. Unpublished PhD Thesis, Victoria University of Wellington, Wellington, New Zealand.

Schmidt, R. (1994). Deconstructing consciousness in search of useful definitions for applied linguistics. In J. H. Hulstijn, \& R. Schmidt (Eds.), Consciousness and Second Language Learning: Conceptual, methodological and practical issues in language learning and teaching (pp.11-26). Thematic issue of AILA Review - Revue de l'AILA.

Schmitt, N., Schmitt, D., Clapham, C. (2001). Developing and exploring the behaviour of two new versions of the Vocabulary Levels Test. Language Testing, 18(1), 55-88.

Schmitt, N. (2010). Researching vocabulary: A vocabulary research manual. Houndmills, Basingstoke, Hampshire [England]; New York;: Palgrave Macmillan.

Shin, D., \& Nation, I. S. P. (2008). Beyond single words: The most frequent collocations in spoken English. ELT Journal, 64, 339-348.

Thomas, M.H. \& Dieter, J.N. (1987). The positive effects of writing practice on integration of foreign words in memory. Journal of Educational Psychology, 79(3), 249-53.

Tian, L., \& Macaro, E. (2012). Comparing the effect of teacher codeswitching with Englishonly explanations on the vocabulary acquisition of Chinese university students: A lexical focus-on-form study. Language Teaching Research, 16(3), 367-391.

Turnbull, M., \& Dailey-O'Cain, J. (2009). First language use in second and foreign language learning. Bristol, U.K; Buffalo, N.Y;: Multilingual Matters.

van der Meer, J. (2012). Students' note-taking challenges in the twenty-first century: Considerations for teachers and academic staff developers. Teaching in Higher Education, 17(1), 13-23. 
VanPatten, B., \& Lee, J. (2003). Making communicative language teaching happen (2nd ed.). New York: McGraw-Hill.

van Zeeland, H., \& Schmitt, N. (2013). Incidental vocabulary acquisition through L2 listening: A dimensions approach. System, 41(3), 609-624.

Vidal, K. (2003). Academic listening: A source of vocabulary acquisition? Applied Linguistics, 24(1), 56-89.

Vidal, K. (2011). A comparison of the effects of reading and listening on incidental vocabulary acquisition. Language Learning, 61(1), 219-258.

Waring, R., \& Takaki, M. (2003). At what rate do learners learn and retain new vocabulary from reading a graded reader? Reading in a Foreign Language, 15(2), 130.

Webb, S. (2007). The effects of repetition on vocabulary knowledge. Applied Linguistics, $28(1), 46-65$.

Webb, S. (2008). Receptive and productive vocabulary size. Studies in Second Language Acquisition, 30(1), 79-95.

Webb, S.A., \& Chang, A, C. (2012). Second language vocabulary growth. RELC Journal, 43(1), 113-126.

Webb, S., \& Chang, A. C. (2015). How does prior word knowledge affect vocabulary learning progress in an extensive reading program. Studies in Second Language Acquisition, 37(4), 651-675.

Webb, S., \& Nation, P. (2017). How Vocabulary is Learned. Oxford: Oxford University Press.

Webb, S., Newton, J., \& Chang, A. C. (2013). Incidental learning of collocation. Language Learning, 63(1), 91-120. 
Webb, S., Sasao, Y., \& Ballance, O. (2017). The updated Vocabulary Levels Test:

Developing and validating two new forms of the VLT. ITL - International Journal of Applied Linguistics, 168(1), 34-70.

Webb, S., \& Piasecki, A. (2018). Re-examining the effects of word writing on vocabulary learning. International Journal of Applied Linguistics, 169(1), 72-94.

White, L. (1987). Against comprehensible input: The input hypothesis and the development of second-language competence. Applied Linguistics, 8(2), 95-110. 


\section{Appendices}

\section{Appendix A: Ethics Approval Notice}

\section{Western Research}

Date: 22 December 2017

To: De. Stuart Webb

Project ID: 110470

Study Title: Incidental Vocabulary Learting through Teacher Talk

Application Type: NMRFB Inital Application

Review Type: Delegated

Full Board Reporting Date: 12/Jan/2018

Date Approval Issued: 22/Dec/2017 15.12

REB Approval Expiry Date: 22/Dec/2018

Dear Dr. Stuart Webb

The Western University Non-Medical Research Ethics Board (NMREB) has reviewed and approved the WREM application form for the above mentioned study, as of the date noted above. NMREEB approval for this study remains valid until the expiry date noted above, conditional to timely subrtission and acceptance of NMREB Continuing Ethics Reviess

This research study is to be conducted by the investigator noted above. All other required institutional approvals must also be obtained prior to the conduct of the stuxty

Documents Approved:

\begin{tabular}{|c|c|c|c|}
\hline Document Name & Document Type & $\begin{array}{l}\text { Document } \\
\text { Date }\end{array}$ & $\begin{array}{l}\text { Document } \\
\text { Version }\end{array}$ \\
\hline $\begin{array}{l}\text { Clean Information letter and Consent Form (version } \\
\text { 2) }\end{array}$ & Written Consent/Assent & $20 \mathrm{Dec} / 2017$ & version2 \\
\hline DEBRIEFING FORM & Debriefing document & & \\
\hline Meaning Recall Test & Paper Survey & $201 \mathrm{De} / 2017$ & version 1 \\
\hline Multiple-choice Test & Paper Survey & $201 \mathrm{Dec} / 2017$ & version 1 \\
\hline New Vocabulary Levels Test & Paper Survey & 201Dec/2017 & version 1 \\
\hline Poster & Recruitment Materials & 21/Dec/2017 & version2 \\
\hline Radio ad script & Recruitment Materials & 19/Dce/2017 & version 1 \\
\hline Script for Classroom Recruitment & Oral Script & 06/Dec/2017 & version 1 \\
\hline Tables & $\begin{array}{l}\text { Supplementary } \\
\text { Tables/Figures }\end{array}$ & & \\
\hline
\end{tabular}

No deviations from, or changes to the protocol should be initiated without prior written approval from the NMREB, except when neoessary to eliminate immediate hazard(s) to study participants or when the change(s) involves only administrative or logistical aspects of the trial

The Western University NMREB operates in complance with the Tri-Council Policy Statement Ethical Conduct for Research Involving Humans (TCPS2), the Ontanio Personal Health Information Protection Act (PHIPA, 2004), and the applicable laws and regulations of Ontario. Members of the NMRFB who are named as Investigators in research studies do not participate in discussions related to, nor vote on such studies when they are presented to the RE:BB. The NMRFB is registered
with the US. Department of Health \& Human Services under the IRB registration number IRB 0000094 ]

Please do not hesitate to contact us if you have any questions

Sincercly,

Katelyn Harris, Research Ethics Otficer on behalf of Dr. Randal Graham, NMREB Chair

Note: This correspondence includes an electronic signature (validation and approval via an online system that is compliant with all regulations). 


\section{Appendix B: Open Questions}

$51 \mathrm{sec}$ : If you have a chance to go abroad, which country do you want to visit?

7min 30sec: Do you have any experiences that are very important in your life or had a great influence on you? If not, just share with us the country or city you've been to and how you feel of it.

12min 30sec: Do you love your university life here? And do you have any plans after graduating?

$21 \mathrm{~min} 54 \mathrm{sec}$ : Can you briefly introduce the food in your hometown or the foods you like? 


\section{Appendix C: Meaning-recall Test}

Please write down the meaning of the words you heard in Chinese. The translation can be a synonym, an explanation, a paraphrase, or anything else you can use to explain the word meaning. If you are not sure about this word, please choose "I don't know".

1.

2 .

3.

4.

5.

6.

7.

8.

9.

10.

11.

12.

13.

14.

15.

16.

17.

18.

19.

20.

21.

22.

23.

24.

25.

26.
I don't know

I don't know

I don't know

I don't know

I don't know

I don't know

I don't know

I don't know

I don't know

I don't know

I don't know

I don't know

I don't know

I don't know

I don't know

I don't know

I don't know

I don't know

I don't know

I don't know

I don't know

I don't know

I don't know

I don't know

I don't know

I don't know 
27.

I don't know

28.

I don't know

29.

I don't know

30.

I don't know

31.

I don't know

32.

I don't know

33.

I don't know

34.

I don't know

35.

I don't know

36.

I don't know 


\section{Appendix D: Multiple-choice Test}

Please circle the right answer based on what you hear to make a phrase; if you are not sure, please choose "I don't know".
Example,
A. move (B.) play
C. run
D. try
I don't know
A. break
B. buy
C. feed
D. pick
I don't know

1. A. take

B. lose

C. make

D. put

I don't know

2. A. lose

B. fall

C. raise

D. reach

I don't know

3. A. have

B. put

C. take

D. use

I don't know

4. A. clear

B. close

C. pretty

D. smal

I don't know

5. A. quick

B. awful

C. fast

D. ready

I don't know

6. A. drop

B. make

C. hold

D. send

I don't know

7. A. far

B. wide

C. hard

D. long

I don't know

8. A. daily

B. extra

C. messy

D. simple

I don't know

9. A. contain

B. gain

C. process

D. receive

I don't know

10. A. add

B. make

C. see

D. feel

I don't know

11. A. find

B. hold

C. pay

D. return

I don't know

12. A. do

B. manage

C. plan

D. prepare

I don't know

13. A. feel

B. keep

C. see

D. show

I don't know

14. A. drop

B. catch

C. hunt

D. miss

I don't know

15. A. feel

B. lose

C. show

D. look

I don't know

16. A. cause

B. make

C. move

D. stop

I don't know

17. A. get

B. take

C. give

D. have

I don't know

18. A. ask

B. make

C. get

D. put

I don't know

19. A. become

B. begin

C. change

D. lose

I don't know

20. A. certain

B. different

C. important

D. simple

I don't know 


\section{Curriculum Vitae}

Name: Zhouhan Jin

Post-secondary East China Normal University

Education and Shanghai, China

Degrees: $\quad$ 2011-2015 B.A.

The University of Western Ontario

London, Ontario, Canada

2016-2018 M.A.

Honours and Western Entrance Scholarship

Awards:

2016-2018

Related Work

English Teacher

Experience: Dongshahu School

Suzhou, China

2015-2016

Chinese Language Instructor

London Chinese School

London, Ontario, Canada

2017-2018 